University of Missouri-Kansas City School of Law

UMKC School of Law Institutional Repository

\title{
Gilead Sciences Sued for Failing to Bring a Follow-On Version of Truvada to Market Sooner.
}

Christopher M. Holman

University of Missouri - Kansas City, School of Law

Follow this and additional works at: https://irlaw.umkc.edu/faculty_works

\section{Recommended Citation}

Christopher M. Holman, Gilead Sciences Sued for Failing to Bring a Follow-On Version of Truvada to Market Sooner., 39 Biotechnology Law Report 267 (2019).

Available at: https://irlaw.umkc.edu/faculty_works/233 
PRE-PRINT VERSION (For print version see Christopher M. Holman, Gilead Sciences Sued for

Failing to Bring a Follow-On Version of Truvada to Market Sooner, 38 BIOTECHNOLOGY LAW REPORT 267 (2019).)

\title{
Gilead Sciences Sued for Failing to Bring a Follow-on Version of Truvada to Market Sooner
}

\author{
Christopher M. Holman*
}

\begin{abstract}
In 2012, the United States Food and Drug Administration (FDA) approved Truvada as the first drug for use in the prevention of HIV infection in healthy people who are at high risk of acquiring HIV through sexual activity. Developed and marketed by Gilead Sciences, Inc., Truvada is a fixed-dose combination of two antiretroviral compounds, tenofovir disoproxil fumarate (TDF) and emtricitabine. The World Health Organization (WHO) has identified both TDF and the combination of TDF and emtricitabine found in Truvada as "essential medicines." In 2015, Gilead began marketing products containing tenofovir alafenamide fumarate (TAF) as a safer and more effective alternative to TDF. Recently, Gilead became the target of multiple lawsuits filed in California state courts accusing the company of negligence, strict product liability, and fraud, based on the company's decision not to bring TAF-based products to market sooner. The plaintiffs are individuals who took TDF-containing products like Truvada and claim that they suffered injury caused by TDF that could have been avoided if a TAF-containing product had been available. Ironically, Congress is currently considering legislation that would make so-called "product hopping" a presumptive antitrust violation. A "product hop" occurs when a drug company brings a "follow-on" version of an already approved drug to market, such as a combination product containing an already approved product (e.g., Truvada), or a new prodrug version of an existing drug (e.g., TAF) . This Article describes Gilead's work developing and marketing tenofovir-based drugs like Truvada, as well as the company's efforts aimed at making the drug more readily available worldwide. It then review the allegations to be found in one of the lawsuits recently filed against Gilead in California. This is followed by a discussion of the proposed legislation intended to deter pharmaceutical product
\end{abstract}

* Christopher M. Holman, Professor of Law, University of Missouri-Kansas City School of Law; Senior Scholar, Center for the Protection of Intellectual Property, Antonin Scalia Law School, George Mason University; and Executive Editor, Biotechnology Law Report. 
PRE-PRINT VERSION (For print version see Christopher M. Holman, Gilead Sciences Sued for Failing to Bring a Follow-On Version of Truvada to Market Sooner, 38 BIOTECHNOLOGY LAW REPORT 267 (2019).)

hopping, including some analysis showing how, if enacted, the proposed legislation could have rendered it a presumptive antitrust violation for Gilead to bring TAF-containing products to market after the company had already begun marketing a TDF-based product.

In 2012, the United States Food and Drug Administration (FDA) approved Truvada as the first drug for use in the prevention of HIV infection in healthy people who are at high risk of acquiring HIV through sexual activity. Developed and marketed by Gilead Sciences, Inc., Truvada is a fixed-dose combination of two antiretroviral compounds, tenofovir disoproxil fumarate (TDF) and emtricitabine. The combination had been approved for use in the treatment of individuals already infected with the HIV virus since 2004. Gilead has marketed one of the components of Truvada, TDF, since 2001 under the tradename Viread for use as a single-active ingredient product for the treatment of HIV (Viread is also approved for use in treating Hepatitis B infection). Truvada and TDF have assumed a prominent role in the global effort to treat and prevent HIV/AIDS, and the World Health Organization (WHO) has identified both TDF and the combination of TDF and emtricitabine found in Truvada as "essential medicines."1

In 2015, Gilead began marketing products containing tenofovir alafenamide fumarate (TAF) as a safer and more effective alternative to TDF. TDF and TAF are prodrugs of tenovovir -both release tenofovir, the actual active ingredient, subsequent to ingestion. However, TAF is effective at lower dosages than TDF, and is believed to be less prone to causing adverse side effects, particularly damage to kidneys, bones, and teeth that has been associated with use of TDF in some patients.

Recently, Gilead became the target of multiple lawsuits filed in California state courts accusing the company of negligence, strict product liability, and fraud, based on the company's decision not to bring TAF-based products to market sooner. The plaintiffs are individuals who took TDFcontaining products like Truvada and claim that they suffered injury caused by TDF that could have been avoided if a TAF-containing product had been available.

Ironically, Congress is currently considering legislation that would make so-called "product hopping" a presumptive antitrust violation. A "product hop" occurs when a drug company brings a "follow-on" version of an already approved drug to market, such as a combination product containing an already approved product (e.g., Truvada), or a new prodrug version of an existing drug (e.g., TAF) . In other words, while Gilead is defending itself in court against allegations based on its failure to bring a follow-on product to market soon enough, Congress is considering legislation that would render the marketing of follow-on products such as Truvada and TAF a presumptive anticompetitive act in violation of the antitrust laws.

${ }^{1}$ World Health Organization, World Health Organization Model List of Essential Medicines (2019), available at https://apps.who.int/iris/bitstream/handle/10665/325771/WHO-MVP-EMP-IAU-2019.06-eng.pdf?ua=1. 
PRE-PRINT VERSION (For print version see Christopher M. Holman, Gilead Sciences Sued for Failing to Bring a Follow-On Version of Truvada to Market Sooner, 38 BIOTECHNOLOGY LAW REPORT 267 (2019).)

At the same time, Gilead is facing mounting criticism from those who believe the company charges too much money for its tenofovir-based products like Truvada, and not doing enough to make the drugs widely available in the U.S. and worldwide. Prompted by this criticism, some are beginning to urge the U.S. government to enforce its own patents against Gilead and to demand up to $\$ 1$ billion in royalties. These patents came out of work done at the U.S. Centers for Disease Control (CDC), apparently in collaboration with Gilead, and purportedly claim the use of Truvada for the prevention of HIV infection in healthy individuals.

This Holman Report describes Gilead's work developing and marketing tenofovir-based drugs like Truvada, as well as the company's efforts aimed at making the drug more readily available worldwide. It then review the allegations to be found in one of the lawsuits recently filed against Gilead in California. This is followed by a discussion of the proposed legislation intended to deter pharmaceutical product hopping, including some analysis showing how, if enacted, the proposed legislation could have rendered it a presumptive antitrust violation for Gilead to bring TAF-containing products to market after the company had already begun marketing a TDF-based product. In fact, bringing the highly touted Truvada to market after Viread could also be considered an anticompetitive product hop, and thus subjected the company to antitrust liability if the proposed legislation was actually the law. The article concludes with some discussion of the controversy surrounding Gilead's alleged infringement of patents owned by the U.S. government, wherein the alleged infringement would be based on instructions that appear on the Truvada label for use of the product to prevent HIV infection in healthy individuals.

\section{Gilead's Development and Marketing of TDF- and TAF-Based Products}

Tenofovir, a nucleotide analog reverse transcriptase inhibitor, was initially synthesized and shown to have anti-HIV activity in the 1980s. However, Tenofovir was found to be poorly absorbed and thus unsuitable for oral administration. Gilead reportedly considered developing and marketing an intravenous formulation of tenofovir, but ultimately scrapped that concept after initial testing revealed that intravenous administration of the compound can impair kidney function. Gilead overcame this obstacle by developing a prodrug of tenofovir, tenofovir disoproxil fumarate (TDF), that can be administered orally and which releases the active tenofovir moiety in the body subsequent to oral administration.

TDF, marketed under the tradename Viread, was approved in the U.S. for the treatment of HIV on October 26, 2001, and for the treatment of chronic hepatitis B on August 11, 2008. The patents on TDF expired in 2018, and in 2017 Teva entered the market with a generic version of Viread. $^{2}$

On August 2, 2004, Gilead gained marketing approval for Truvada, a fixed-dose combination of TDF and emtricitabine. The Orange Book identifies two patents associated with Truvada, one of them claims emtricitabine per se, the other claims the enantiomer of emtricitabine used in

${ }^{2}$ Letter from FDA to TEVA USA Re: ANDA 091612, dated March, 18, 2015, available at https://www.accessdata.fda.gov/drugsatfda_docs/appletter/2015/091612Orig1s000ltr.pdf. 
PRE-PRINT VERSION (For print version see Christopher M. Holman, Gilead Sciences Sued for Failing to Bring a Follow-On Version of Truvada to Market Sooner, 38 BIOTECHNOLOGY LAW REPORT 267 (2019).)

Truvada. Both patents were originally assigned to Emory University, and have presumably been exclusively licensed by Gilead. According to Gilead, the company has spent an estimated \$1.1 billion dollars bringing Truvada to market. ${ }^{3}$ The company followed up Truvada with three subsequent combination products, each comprising TDF and emtricitabine plus one or more additional active ingredients - Atripla (approved July 12, 2006), Complera (approved August 10, 2011), and Stribild (approved August 27, 2012).

Although TDF drugs were initially approved for use in the treatment of individuals already infected with the HIV virus, it was later shown that the drugs could be used prophylactically to prevent infection in individuals that are exposed to HIV virus, a practice commonly referred to as pre-exposure prophylaxis, or "PrEP." TDF drugs have achieved great success in treating and preventing HIV infection. Both TDF and the combination of emtricitabine and tenofovir (the active ingredients in Truvada) are on the World Health Organization's list of "essential medicines," which the WHO defines as the "minimum medicine needs for a basic health-care system, listing the most efficacious, safe, and cost-effective medicines for priority conditions." 4 Truvada has achieved blockbuster status, generating \$2.8 billion in revenue in 2018 in the U.S. alone, ${ }^{5}$ and a reported $\$ 36.2$ billion between 2004 and $2015 .{ }^{6}$

In 2015, Gilead began to market a series of new anti-retroviral products the employ a different prodrug of tenofovir, tenofovir alafenamide fumarate (TAF). TAF is reportedly more safe and effective than TDF, and is thought to be less likely to result in the harm to bones and kidneys associated with the use of TDF in some individuals. Vemlidy is the tradename for the Gilead's single-active ingredient TAF product, which was approved in November 2016 for use in the treatment of hepatitis B virus (but apparently not for HIV). ${ }^{7}$ The first TAF-based product to receive FDA marketing approval for treatment of HIV infection was Genvoya, approved November 2015, which is essentially an improved version of Stribild in which the TDF has been replaced with TAF. Similarly, Odefsey, which was approved on March 1, 2016, is Complera with TAF instead of TDF. Descovy, approved on April 4, 2016, is Truvada with TAF instead of TDF. Most recently, Biktarvy, which is a combination of Descvoy and bictegravir, was

\footnotetext{
${ }^{3}$ Gilead Sciences, Gilead Sciences Statement On Inaccurate Reporting On Truvada® (2019), available at https://www.gilead.com/news-and-press/company-statements/gilead--sciences--statement--on--inaccurate-reporting--on--truvada “(The company has spent an estimated \$1.1 billion on R\&D related to Truvada - to develop the two individual drugs that make up Truvada, invent the combination product that is Truvada, invent its use for HIV treatment and support the clinical trials that led to the approval of Truvada for PrEP”).

${ }^{4}$ World Health Organization, World Health Organization Model List of Essential Medicines (2019), available at https://apps.who.int/iris/bitstream/handle/10665/325771/WHO-MVP-EMP-IAU-2019.06-eng.pdf?ua=1.

${ }^{5}$ Generics and Biosimilars Initiative, Gilead's Truvada will face generics competition in 2020 (2019), available at http://www.gabionline.net/Generics/General/Gilead-s-Truvada-will-face-generics-competition-in-2020.

${ }^{6}$ Timothy Williams et al. v. Gilead Sciences, San Diego Superior Court, Docket No. 2019-00035536.

${ }^{7}$ Gilead Sciences, U.S. Food and Drug Administration Approves Gilead's Vemlidy® (Tenofovir Alafenamide) for the Treatment of Chronic Hepatitis B Virus Infection (2016), available at https://www.gilead.com/news-andpress/press-room/press-releases/2016/11/us-food-and-drug-administration-approves-gileads-vemlidy-tenofoviralafenamide-for-the-treatment-of-chronic-hepatitis-b-virus-infection.
} 
PRE-PRINT VERSION (For print version see Christopher M. Holman, Gilead Sciences Sued for Failing to Bring a Follow-On Version of Truvada to Market Sooner, 38 BIOTECHNOLOGY LAW REPORT 267 (2019).)

approved November 7, 2018. As of yet, none of the TAF-based products has been approved for use in preventing HIV infection.

\section{Gilead's Efforts to Combat HIV/AIDS}

As recounted in a complaint recently filed in a lawsuit against Gilead (which is the focus of the next section of this article), Gilead began investigating and developing tenofovir prodrugs for use in the treatment of HIV/AIDS at a time when the HIV/AIDS community was faced with an overall lack of treatment options and astronomical prices for the few available medications, and the rest of the pharmaceutical industry was neglecting the disease. Not only has Gilead developed and brought to market multiple essentials medicines used in the fight against HIV/AIDS, the company has taken a leading role in combating the disease worldwide.

For example, a report published by Funders Concerned About AIDS (FCAA) in 2015 ranked Gilead Sciences as the leading corporate global funder of HIV/AIDS programs, second overall behind the Bill \& Melinda Gates Foundation. ${ }^{8}$ Gilead was also identified in the report as the top corporate funder in several subcategories, including philanthropy to address HIV in the United States and giving to support vulnerable populations, such as men who have sex with men and people who inject drugs. On September 27, 2018, Gilead announced that it will provide grant funding to the Spouses of CARICOM Leaders Action Network (SCLAN) to help expand access to HIV prevention and treatment for adolescents and young adults, particularly those at high risk for HIV infection in the Caribbean. ${ }^{9}$ And in September, 2019, Gilead and the Elton John AIDS Foundation announced the launch of the RADIAN, which seeks to address new HIV infections and deaths from AIDS-related illnesses in Eastern Europe and Central Asia (EECA). ${ }^{10}$ According to UNAIDS, while rates of new HIV infections and deaths from AIDS-related illnesses are now decreasing globally, EECA is one of the few regions where HIV is on the rise and deaths from AIDS have increased by approximately 300 percent in the last 20 years.

On May 9, 2019, Gilead announced that it will donate up to 2.4 million bottles of Truvada to the CDC for use by uninsured Americans at risk for HIV. ${ }^{11}$ The donation, which extends up to 2030, will transition to Descovy (the TAF-containing analog of Truvada) if it is approved for use in PrEP.

\footnotetext{
${ }^{8}$ Funders Concerned about AIDS, Philanthropic Support to Address HIV/AIDS 2015 (2016), available at https://www.fcaaids.org/wp-content/uploads/2016/11/FCAA_2016TrackingReport_web-1.pdf.

${ }^{9}$ Gilead Sciences, Gilead Sciences Statement on Grants to Spouses of Caricom Leaders Action Network (SCLAN) to Expand Access to Youth HIV Prevention and Care in the Caribbean (2018), available at https://www.gilead.com/news-and-press/company-statements/grants-for-sclan.

${ }^{10}$ Gilead Sciences, Gilead Sciences and the Elton John AIDS Foundation Launch RADIAN Initiative to Address HIV in Eastern Europe and Central Asia (EECA) (2019), available at https://www.gilead.com/news-and-press/pressroom/press-releases/2019/9/gilead-sciences-and-the-elton-john-aids-foundation-launch-radian-initiative-to-addresshiv-in-eastern-europe-and-central-asia-eeca

${ }^{11}$ Gilead Sciences, Gilead Sciences to Provide Free Truvada for PrEP ${ }^{\circledR}$ to Support U.S. Initiative to End the HIV Epidemic, (2019), available at https:/www.gilead.com/news-and-press/press-room/press-releases/2019/5/gileadsciences-to-provide-free-truvada-for-prep-to-support-us-initiative-to-end-the-hiv-epidemic
} 
PRE-PRINT VERSION (For print version see Christopher M. Holman, Gilead Sciences Sued for Failing to Bring a Follow-On Version of Truvada to Market Sooner, 38 BIOTECHNOLOGY LAW REPORT 267 (2019).)

\section{Allegations Contained in the Lawsuits Filed Against Gilead}

As of July 8, 2019 Gilead had reportedly become the subject of 26 lawsuits that have been filed in state courts in nine counties in California accusing Gilead of harming individuals who took TDF-based products by failing to make TAF-based products available to patients sooner, allegedly so that the company could profit from the marketing of the less-safe TDF prodrug. ${ }^{12}$ To gain some insight into the nature of the allegations, let us look at the complaint that was filed in connection with one of those lawsuits, Timothy Williams et al. v. Gilead Sciences. ${ }^{13}$ The complaint was filed in the Superior Court in San Diego on July 10, 2019, and accuses Gilead of negligence, strict product liability, breach of express and implied warranties, and fraud and concealment. $^{14}$

More particularly, the complaint allege that Gilead synthesized TDF and TAF simultaneously in1993, and that by 1998 the company had concluded initial preclinical studies and animal testing that revealed the two prodrugs' relative potency, efficacy and cytotoxicity. Through these studies, Gilead allegedly learned that the conversion of TDF to pharmaceutically-active tenofovir subsequent to oral ingestion occurs relatively inefficiently in the human body, and as a result the amount of active ingredient absorbed into the bloodstream is disproportionately low compared to the dose of TDF administered. As a consequence of this low bioavailability, Gilead determined that a $300 \mathrm{mg}$ dose of TDF was necessary to achieve the desired inhibition of HIV-1. Gilead further determined, according to the complaint, that this minimal effective dose of TDF resulted in abnormally high concentration of tenofovir in the kidneys, which inhibits the overall ability of the kidneys to function properly and contributes to mineral losses that precede bone and tooth loss.

The complaint goes on to allege that at the time Gilead reached these conclusions regarding the potential for adverse events associated with the use of TDF, it also determined that TAF is a more viable prodrug that could be administered orally to introduce the same amount of active tenofovir in the body at one-tenth the dosage of prodrug, and that TAF could achieve the same anti-retroviral effectiveness as TDF at only one-thousandth of the dose. Consistent with this allegation regarding relative efficacy, Vimeldy contains $25 \mathrm{mg}$ of TAF per capsule, while its TDF-based counterpart Viread contains $300 \mathrm{mg}$ of that drug per capsule, a 12-fold difference. Similarly, Stribild contains $300 \mathrm{mg}$ of TDF, while its counterpart Genvoya contains $10 \mathrm{mg}$ TAF, a 30-fold difference.

The complaint further alleges that publications “dating back to 2001, or even 1997," showed that TAF is safer, more effective, and a better overall drug compared to TDF, and that throughout the time Gilead was developing TDF-based drugs the company knew that TDF was extremely toxic to kidneys, bones and teeth. It also alleges that data submitted in 2000 by the company in a

\footnotetext{
${ }^{12}$ Valerie Bauman, Gilead Withheld Safer HIV Drugs from Market, Lawsuit Claims, Bloomberg Law (Jul. 8, 2019).

${ }^{13}$ Timothy Williams et al. v. Gilead Sciences, San Diego Superior Court, Docket No. 2019-00035536.

${ }^{14} \mathrm{Id}$.
} 
PRE-PRINT VERSION (For print version see Christopher M. Holman, Gilead Sciences Sued for Failing to Bring a Follow-On Version of Truvada to Market Sooner, 38 BIOTECHNOLOGY LAW REPORT 267 (2019).)

patent application (presumably relating to TAF) revealed that Gilead knew that TAF was substantially less toxic than TDF.

According to the complaint, Gilead shelved the TAF project in 2004, and "strategically" waited until 2014, when patent protection for TDF was due to expire shortly, to apply for FDA approval of a TAF product, which it brought to market for the first time in November 2015 in the form of Genvoya (the TDF-based analog of Truvada). The plaintiffs charge that "Gilead's intentional, knowing, willful, reckless and/or careless promotion of the less effective, less safe TDF over TAF allowed Gilead to artificially extend the period during which it could exclusively manufacture and sell tenofovir-based drugs for use in preventing and/or treating HIV-1.”

The plaintiffs named in the complaint were all using TDF-based products like Truvada for PrEP, not for the treatment of HIV infection. I would assume that the plaintiff's attorneys chose these particular patients because any valid assessment of drug safety must weigh the benefit of a drug versus the risk of adverse effects, and the benefit of a TDF-based product would generally be less for a patient who is not infected with HIV at the time of administration, given that the drug is being used as a prophylactic rather than for the treatment of the disease.

The complaint further alleges that in addition to its own internal research and conclusions regarding the safety and efficacy of TDF, Gilead was aware of post-market clinical studies and adverse event reports from as early as 2002, that were unavailable to the general public, and which allegedly documented TDF's association with severe renal deficiencies and toxicity in patients without any pre-existing history of kidney problems, as well as acute decreases in bone mineral density and tooth loss. The complaint alleges that as these reports of TDF-related injuries began to emerge in 2002, Gilead contemporaneously funded TAF clinical research throughout the country, which continued to confirm that TAF is both more effective and less toxic to patients' kidneys, bones, and teeth.

The plaintiffs further allege that Gilead suppressed the publication of research reporting TDFrelated adverse events, and that the company continued to maintain in their marketing materials and sales presentations that TDF was a "risk-free" "miracle drug" for the treatment of HIV-1. Moreover, the company is accused of falsely claiming that TAF was not different enough from TDF to warrant further development, and of announcing in 2004 that the company would abandon TAF in its future plans to design and produce antiretroviral drugs for the treatment of HIV-1.

The complaint documents mounting evidence prior to 2012 which purportedly put Gilead on notice of the safety concerns associated with TDF-based drugs. This includes a 2006 Conference on Retroviruses and Opportunistic Infections in which CDC investigators reportedly presented data obtained from 11,362 HIV-infected patients that had been treated with TDF-based medications, and concluding that TDF was associated with mild and moderate renal insufficiency. A post-2006 observational study of 497 HIV-infected patients initiating TDF treatment purportedly showed that nearly $20 \%$ developed significant renal dysfunction. The 
PRE-PRINT VERSION (For print version see Christopher M. Holman, Gilead Sciences Sued for Failing to Bring a Follow-On Version of Truvada to Market Sooner, 38 BIOTECHNOLOGY LAW REPORT 267 (2019).)

complaint alleges that multiple articles published between 2008 and 2011 continued to show that TDF caused marked decreases in kidney functions.

The complaint further alleges that these findings prompted FDA to require Gilead to modify its Viread label on at least seven separate occasions between 2002 and 2008 to more accurately describe the risks of kidney damage experienced by patients taking TDF. It goes on to state that in spite of the evidence, Gilead's prescribing information for Truvada continued to distort the risk of renal injury and bone loss as primarily a concern for patients with pre-existing renal and bone density conditions.

The plaintiffs allege that, in spite of the mounting evidence, Gilead did not begin Phase II clinical trials of TAF-based medications until January 2012, and that by October 2012 these clinical trials had shown that a once daily single tablet containing only $10 \mathrm{mg}$ of TAF-based medication demonstrated better markers of bone and kidney effects when compared with the 300 mg dose of TDF found in Stribild.

It was only then, as Gilead's TAF-based products moved into Phase III clinical trials, that the company transitioned from "downplaying the differences between TDF and TAF to proclaiming the latter as a "new" and "better" drug for the treatment of HIV-1. Even more shocking, according to the complaint, was "Gilead's bold reliance on TAF data obtained by the company before 2005 showing that: (1) TAF provided greater intracellular distribution of tenofovir while yielding lower plasma tenofovir levels than TDF; (2) TAF was less likely to accumulate in the renal proximal tubules, leading to improved overall safety profile; and (3) TAF doses were far lower than necessary for equivalent TDF-based medications.”

\section{Anti-Product Hopping Legislation Currently Being Considered by \\ Congress}

Ironically, while the lawsuits discussed above allege that Gilead injured patients by failing to bring TAF to market soon enough, legislation was recently introduced in Congress that, if it had been the law during the relevant time frame, would have created a rebuttable presumption that by bringing a follow-on product like TAF to market Gilead had violated U.S. antitrust law. The legislation is the Affordable Prescriptions for Patients Act of 2019, S. 1416, introduced by Senators John Cornyn and Richard Blumenthal on May 9, 2019. The overall intent of the bill is to bring down the cost of drugs, by making it an antitrust violation for pharmaceutical innovators to engage in certain activities that allegedly allow the innovators to delay generic competition in a manner that keeps drug prices high. These activities include so-called "patent thicketing," a pejorative term applied to a drug company that secures what some would consider to be "too many patents," and "product hopping," which is how critics often characterize a pharmaceutical innovator's decision to bring a new version of an existing drug to market. Examples of producthopping would include bringing to market a new prodrug such as TAF, or a fixed-dosage 
PRE-PRINT VERSION (For print version see Christopher M. Holman, Gilead Sciences Sued for Failing to Bring a Follow-On Version of Truvada to Market Sooner, 38 BIOTECHNOLOGY LAW REPORT 267 (2019).)

combination product like Truvada that contains one or more previously marketed active ingredients. $^{15}$

Some critics of the patenting practices of pharmaceutical companies have argued that product hopping is nothing more than a ploy used by pharmaceutical companies to "evergreen" patent exclusivity, i.e., to extend patent protection beyond the term of the original patent or patents on a drug product. For instance, Professor Robin Feldman has described “product hopping” as a variant of evergreening. ${ }^{16}$ As she explains it, a product hop occurs when a brand-name drug company makes a "small change" to an existing patented drug, such as a new form, formulation, or dosage of the drug, patents that change, and then just as the patent on the original drug is set to expire, the drug company "forces a market shift away from the old drug" by convincing doctors to prescribe the new version of the drug, patients to use that new version, and insurers to pay for it. ${ }^{17}$ This "forced" market shift is accomplished, according to Professor Feldman and others who share her views, by the branded company advertising and promoting the new product, convincing doctors to prescribe it, providing significant rebates and discounts to patients and third-party payers, and in some cases discontinuing the previous version of the drug.

The notion that product hopping is an unfair method of competition has moved beyond academic commentators, and a number of plaintiffs have brought antitrust lawsuits against pharmaceutical companies based on an allegedly anticompetitive product hop. For the most part, however, courts presented with allegations that product hopping constitutes an antitrust violation have found that bringing a new pharmaceutical product to market, in and of itself, does not create antitrust liability. ${ }^{18}$ Courts have held, for example, that the antitrust laws do not require a pharmaceutical company to show that a new product is somehow superior to earlier versions of the drug. ${ }^{19}$ Court have, however, found that bringing a new product to market, when combined with other actions intended to improperly coerce patients to switch to the new product, can constitute an antitrust violation. Examples have included withdrawing the earlier product from the market for no apparent reason other than to stymie competition, buying back supplies of the old formulation combined with changing product codes for the old product to "obsolete" to prevent pharmacies from filling prescriptions with generic versions of the old formulation, or fabricating safety concerns about the earlier product. ${ }^{20}$

\footnotetext{
${ }^{15}$ Viread (TDF) was approved in 2001, Emtriva (emtricitabine) was approved in 2003, and Truvada (TDF + emtricitabine) was approved in 2004.

${ }^{16}$ Feldman, Robin and Frondorf, Evan, Drug Wars: A New Generation of Generic Pharmaceutical Delay, 53 Harv.

J. on Legis. 500 (2016).

${ }^{17} \mathrm{Id}$.

${ }^{18}$ Michael Gallagher et al., United States: Pharmaceutical Antitrust, White \& Case LLP website (2019), available at https://www.whitecase.com/sites/whitecase/files/files/download/publications/us-pharmaceutical-antitrust-2019.pdf.

${ }^{19} \mathrm{Id}$.

${ }^{20} I d$.
} 
PRE-PRINT VERSION (For print version see Christopher M. Holman, Gilead Sciences Sued for Failing to Bring a Follow-On Version of Truvada to Market Sooner, 38 BIOTECHNOLOGY LAW REPORT 267 (2019).)

The concern that product hopping is facilitating the wrongful evergreening of patent protection clearly influenced the Affordable Prescriptions for Patients Act. A background document provided by the bill's sponsors states:

Product Hopping takes advantage of our current FDA approval system to get around pharmacy-level generic substitution laws. When making a new version of a drug, like a minor reformulation, that new drug can't be substituted for the generic, because the generic is tied to the old version. Sometimes the manufacturer will go so far as to remove the old version from the market completely. This leaves the generic with nowhere to go, as patients are forcibly switched to the new version. ${ }^{21}$

In particular, the Affordable Prescriptions for Patients Act would make it a prima facie antitrust violation (more particularly, an "unfair method of competition in or affecting commerce in violation of section 5(a)") for a manufacturer of a reference product (on which a biosimilar biologics license application (BLA) under 24 USC §262 is based) or an Orange Book-listed drug to take one of the following two actions during the relevant time frames:

(1) cause FDA to discontinue or withdraw the "reference drug’s"22 application (or announce discontinuance of or withdrawal of the application) during the period beginning on the date on which the manufacturer of the reference drug receives notice that an applicant has submitted an abbreviated new drug application (ANDA) or biosimilar BLA and ending on the date that is 180 days after the date on which that generic drug or biosimilar product first enters, or could enter, the market, or is denied; or

(2) market or sell a follow-on product during a period of time referred to as the "competition window."

With respect to an Orange Book-listed drug, the term 'competition window' is defined as the period between:

(1) the date that is the earlier of (a) 8 years before any patent or marketing exclusivity granted with respect to such listed drug expires; and (b) the date on which the first ANDA that references such listed drug is filed; and

(2) the date that is the later of (a) 180 days after the ANDA that references such listed drug is filed; and (b) 1 year after the date on which the generic drug that is the subject of the ANDA enters the marketplace.

\footnotetext{
${ }^{21}$ Steve Brachmann, Affordable Prescriptions for Patients Act Would Allow FTC to Prosecute Pharma Patent Thickets, Product Hopping, IP Watchdog (May 20, 2019), available at https://www.ipwatchdog.com/2019/05/20/affordable-prescriptions-patients-act-allow-ftc-prosecute-pharmaceuticalpatent-thickets-product-hopping/id=109384/.

22 The bill does not define the term "reference drug," but its usage indicates that it refers to a listed drug or reference product.
} 
PRE-PRINT VERSION (For print version see Christopher M. Holman, Gilead Sciences Sued for Failing to Bring a Follow-On Version of Truvada to Market Sooner, 38 BIOTECHNOLOGY LAW REPORT 267 (2019).)

Similarly, with respect to a biological reference product the term 'competition window' is defined as the period between:

(1) the date that is the earlier of (a) 6 years before any patent or marketing exclusivity granted with respect to such reference product expires; and (b) the date on which the first biosimilar BLA that references such reference product is filed; and

(2) the later that is the later of (a) 180 days after the date on which the first biosimilar BLA that references such reference product enters the marketplace; and (b) 1 year after the date on which the biosimilar biological product that is the subject of the biosimilar BLA enters the marketplace.

The term 'follow-on product' is defined as an approved drug or biological product that represents a "change, modification, or reformulation" to the same manufacturer's previously approved drug or biological product.

A manufacturer can rebut the prima facie case of unfair competition arising from the discontinuance or withdrawal of a reference product's application by demonstrating the drug was removed from the market for "significant and documented safety reasons."

In a case in which a manufacturer has brought a follow-on product to market during the competition window, the prima facie case of unfair competition can be rebutted by demonstrating that:

(1) the follow-on product provides a clinically meaningful and significant additional health benefit to the target population beyond that provided by the previously approved drug or biological product;

(2) the follow-on product was the available means that was least likely to reduce competition; and

(3) the manufacturer had substantive financial reasons, apart from the financial effects of reduced competition, to introduce the follow-on product to the market.

In making this demonstration, the manufacturer must provide to the Federal Trade Commission (FTC):

(1) all research and development, manufacturing, marketing, and other related costs associated with the previously approved drug or biological product, including all documents, memos, or other business documents that explain, mention, or otherwise justify the decision of the manufacturer to develop and manufacture the follow-on product; and

(2) the revenue obtained by the manufacturer with respect to the previously approved drug or biological product drug and the "expected revenue” of the manufacturer with respect to the previously approved drug or biological product and the follow-on product. 
PRE-PRINT VERSION (For print version see Christopher M. Holman, Gilead Sciences Sued for Failing to Bring a Follow-On Version of Truvada to Market Sooner, 38 BIOTECHNOLOGY LAW REPORT 267 (2019).)

The term 'expected revenue', with respect to a follow-on product, means the financial value represented by the number of individuals in the target population multiplied by the financial revenue generated by each member of the target population over the 3-year period beginning:

(1) on the day that 3 generic drugs referencing the same listed drug or 2 or more biosimilar biological products referencing the same reference product would have been widely available in the market; or

(2) if 3 or more generic drugs referencing the same listed drug or 2 or more biosimilar biological products referencing the same reference product are already widely available in the market, the day that the follow-on product enters the market.

The term "target population" means the population of individuals that

(1) would experience a significant health improvement from a follow-on product; and

(2) would have bought the follow-on product solely because of the significant health improvement that those individuals would experience.

\section{Applying the Proposed Legislation to Gilead's Tenofovir-Based Medicines}

A prodrug like TAF would very likely constitute a "follow-on product" under the Affordable Prescriptions for Patients Act, since it represents a "change, modification, or reformulation" of the previously approved TDF-based products. The evergreening literature clearly identifies prodrugs as the sort of "secondary" pharmaceutical innovation that pharmaceutical companies have allegedly used to improperly extend patent exclusivity. ${ }^{23}$ According to the FDA, the patents on TDF expired in 2018. ${ }^{24}$ Under the legislation it would have been a presumptive antitrust violation for Gilead to have brought a TAF-based product to market during the "competition window" that would have begun no later than eight years prior to patent expiration, i.e., 2010, and extended to at least 2017, when Teva entered the market with generic Viread.

Of course, in retrospect it appears likely that Gilead would have been able to rebut the presumption of anticompetitive conduct, by presenting evidence that TAF is substantially superior to TDF in terms of safety and efficacy. But doing so would have been burdensome and intrusive. In particular, Gilead would have been required to prove that TAF provides a clinically meaningful and significant additional health benefit to the target population beyond that provided by TAF, that TAF was the available means that was least likely to reduce competition, and that the company had substantive financial reasons, apart from the financial effects of reduced competition, to introduce TAF to the market. In making this demonstration, Gilead would have been required to provide the FTC with "all research and development, manufacturing, marketing,

\footnotetext{
${ }^{23}$ See, e.g., Amy Kapczynski, Chan Park \& Bhaven Sampat, Polymorphs and Prodrugs and Salts (Oh My!): An Empirical Analysis of 'Secondary' Pharmaceutical Patents, 7 PLOS ONE 1,1 (2012). (characterizing a prodrug as a "minor modification[] of the structure or chemical makeup of a molecule.")

${ }^{24}$ Letter from FDA to TEVA USA Re: ANDA 091612, dated March, 18, 2015, available at https://www.accessdata.fda.gov/drugsatfda_docs/appletter/2015/091612Orig1s000ltr.pdf.
} 
PRE-PRINT VERSION (For print version see Christopher M. Holman, Gilead Sciences Sued for Failing to Bring a Follow-On Version of Truvada to Market Sooner, 38 BIOTECHNOLOGY LAW REPORT 267 (2019).)

and other related costs associated with [TDF], including all documents, memos, or other business documents that explain, mention, or otherwise justify the decision of the manufacturer to develop and manufacture [TAF]; and the revenue obtained by the manufacturer with respect to [TDF] and the expected revenue of the manufacturer with respect to [TDF] and [TDF].”

It bears noting that Gilead's marketing of Truvada and the other fixed-dose combination products containing TDF would have also triggered the presumption of antitrust violation under the statute if these follow-on products had been brought to market during the competition window. Combination products that combine two drugs in a single product have been particularly targeted by critics of pharmaceutical innovators. For example, the Guidelines for Pharmaceutical Patent Examination: Examining Pharmaceutical Patents from a Public Health Perspective, issued by the United Nations Development Programme, provides the following "recommendation":

Combinations of known drugs may be considered a method of treatment and hence be deemed non-patentable because they lack industrial applicability or are excluded from protection under national law. In some cases, combination claims do not meet the novelty standard, such as when the combination was previously known and practised by the medical profession. In addition, such a combination will not satisfy the inventive step standard, unless a synergistic effect, justified by appropriate clinical tests, can be demonstrated. However, synergistic effects that may be reasonably expected from the combination of two or more drugs of known therapeutic classes do not meet the inventive step standard. ${ }^{25}$

With critics essentially arguing that combination products should generally be found unpatentable, it seems likely that Gilead would have had a hard time convincing the FTC that Truvada provides sufficient additional benefits to patients to overcome the presumption of anticompetitive effect, particularly given the zeal with which FTC has gone after pharmaceutical innovators in recent years. Of course, the notion that fixed dosage combination products such as Truvada provide no patient benefit is entirely at odds with the World Health Organization's designation of the fixed combination of TDF and emtricitabine found in Truvada is an "essential medicine.” I have argued in previous articles that combination products can provide significant benefit to patients, and have identified cases where courts have come to the same conclusion. ${ }^{26}$

\footnotetext{
${ }^{25}$ Carlos M. Correa, Guidelines for Pharmaceutical Patent Examination: Examining Pharmaceutical Patents from a Public Health Perspective, UNDP (2015).

${ }^{26}$ Christopher M. Holman, In Defense of Secondary Pharmaceutical Patents: A Response to the UN's Guidelines for Pharmaceutical Patent Examination, 50 Indiana Law Review 759 (2017).
} 
PRE-PRINT VERSION (For print version see Christopher M. Holman, Gilead Sciences Sued for Failing to Bring a Follow-On Version of Truvada to Market Sooner, 38 BIOTECHNOLOGY LAW REPORT 267 (2019).)

\section{Allegations That Gilead Is Infringing Patents Owned by the U.S. Government}

In March 2019, the Yale Global Health Justice Partnership (GHJP) published a "Statement on CDC's Patents for PrEP” which identifies three patents assigned to the U.S. Department of Health and Human Services, and naming inventors affiliated with the Centers for Disease Control (CDC), which claim the use of a combination of emtricitabine and TDF, i.e., Truvada, for pre-exposure prophylaxis (PReP). ${ }^{27}$ According to the GHJP statement, Gilead appears to be infringing the patents by including instructions on the Truvada label for using the drug for PReP, and the U.S. government could assert the patents against Gilead and seek money damages. HIV activists are reportedly urging the U.S. government to enforce these patents against Gilead and force the company to pay royalties for its sale of Truvada for PrEP, with the money to be used to fund education and distribution programs to expand the usage of the drug. ${ }^{28}$ Perhaps in response to this pressure, the Department of Justice (DOJ) is reportedly investigating whether Gilead is infringing these patents.

In August, 2019, Gilead announced that it has submitted petitions to the U.S. Patent and Trademark Office requesting an inter partes review of the HHS's patents claiming HIV preexposure prophylaxis (PrEP) and post-exposure prophylaxis (PEP). ${ }^{29}$ In a press release, Gilead asserts that the claims are invalid, in view of published materials "clearly show[ing] that well before HHS claims to have invented the concepts of PrEP and PEP in 2006, others had conceived of using an antiretroviral therapy, including Truvada ${ }^{\circledR}$, for both forms of prophylaxis.” According to Gilead, it collaborated with the CDC on PrEP studies that apparently led to these patents, including providing Truvada free of charge for use in the non-human primate studies that were the basis of the CDC's patents. ${ }^{30}$

\section{Conclusion}

Gilead's experiences illustrate the conflicting pressures being brought to bear on pharmaceutical innovators. While critics concerned about the cost of drugs and intent upon switching consumers to cheaper generics seek to limit the ability of drug companies to bring follow-on products to

\footnotetext{
${ }^{27}$ Yale Global Health Justice Partnership, Summary of Statement on CDC's Patents for PrEP (2019), available at https://law.yale.edu/sites/default/files/area/center/ghjp/documents/ghjp_2-page_statement_on_cdc_patents_final.pdf.

${ }^{28}$ Christopher Rowland, An HIV treatment cost taxpayers millions. The government patented it. But a pharma giant is making billions, Washington Post (2019), available at https://www.washingtonpost.com/business/economy/pharma-giant-profits-from-hiv-treatment-funded-by-taxpayersand-patented-by-the-government/2019/03/26/cee5afb4-40fc-11e9-9361-301ffb5bd5e6_story.html.

${ }^{29}$ Gilead Sciences, Gilead Statement on Petitions to US Patent and Trademark Office on HIV PrEP Patents (2019), available at https://www.gilead.com/news-and-press/company-statements/petitions-to-us-patent-and-trademarkoffice-on-hiv-prep-patents.

${ }^{30}$ Christopher Rowland, An HIV treatment cost taxpayers millions. The government patented it. But a pharma giant is making billions, Washington Post (2019), available at https://www.washingtonpost.com/business/economy/pharma-giant-profits-from-hiv-treatment-funded-by-taxpayersand-patented-by-the-government/2019/03/26/cee5afb4-40fc-11e9-9361-301ffb5bd5e6_story.html.
} 
PRE-PRINT VERSION (For print version see Christopher M. Holman, Gilead Sciences Sued for Failing to Bring a Follow-On Version of Truvada to Market Sooner, 38 BIOTECHNOLOGY LAW REPORT 267 (2019).)

market, products liability lawyers file lawsuits alleging that Gilead has injured patients for failure to bring a follow-on product to market. Gilead's collaboration with the CDC to demonstrate the efficacy of Truvada in preventing HIV infection results in patents that could result in Gilead being found liable for patent infringement based solely on the company's efforts to gain FDA approval for the use of Truvada in PrEP. Pharmaceutical innovation is a challenging undertaking, especially in the area of essential medicines, and with the current emphasis on bringing down the cost of drugs, it seems destined to become even more difficult in the future. ${ }^{31}$

${ }^{31}$ See, e.g., Christopher M. Holman, Congress Considering Legislation Aimed at Increasing Competition in Pharmaceuticals, 38 Biotechnology L. Rep. 144 (2019). 